\title{
The Cyclical Behavior of the Beveridge Curve in the
}

\section{Housing Market*}

\author{
Miroslav Gabrovski ${ }^{\dagger} \quad$ Victor Ortego-Marti ${ }^{\ddagger}$
}

This Version: January 31, 2019

\begin{abstract}
This paper develops a business cycle model of the housing market with search frictions and entry of both buyers and sellers. The housing market exhibits a well-established cyclical component, which features three stylized facts: prices move in the same direction as sales and the number of houses for sale, but opposite to the time it takes to sell a house. These stylized facts imply that in the data housing vacancies and the number of buyers are positively correlated, i.e. that the Beveridge Curve is upward sloping. A baseline search and matching model of the housing market is unable to match these stylized facts because it inherently generates a downward sloping Beveridge Curve. With free entry of both buyers and sellers, our model reproduces the positive correlation between prices, sales and vacancies, and matches the stylized facts qualitatively and quantitatively.
\end{abstract}

JEL Classification: E2, E32, R21, R31.

Keywords: Housing market; business cycles; search and matching; Beveridge Curve.

\footnotetext{
*We are grateful to the Editor Laura Veldkamp, two anonymous referees, Richard Arnott, Thanasis Geromichalos, Jang-Ting Guo, Berthold Herrendorf, Ayse Imrohoroglu, David Lagakos, Kevin Lansing, Lee Ohanian, Nicolas Petrosky-Nadeau, Vincenzo Quadrini, Romain Rancière, Victor Rios-Rull, Guillaume Rocheteau, Henry Siu, Eric Smith and Alwyn Young for their insightful comments and suggestions. We also thank seminar participants at the 16th West Coast Search and Matching Workshop, CSU Fullerton, UC Irvine and UC Riverside for helpful discussions. An earlier version of this paper was circulated under the title "Housing Market Dynamics with Search Frictions".

${ }^{\dagger}$ Department of Economics, University of Hawaii Manoa. 2424 Maile Way, Saunders Hall 516, Honolulu, HI 96822, USA. Email: mgabr@hawaii.edu.

${ }_{\ddagger}^{\ddagger}$ Department of Economics, University of California Riverside. Sproul Hall 3132, Riverside CA 92521, USA. Email: victor.ortego-marti@ucr.edu.
} 


\section{Introduction}

One salient feature of the housing market is that, similar to the labor and marriage markets, it is subject to search frictions. It takes time for households to find a suitable house and for sellers to find a buyer for their vacancy. Both sellers and buyers must spend costly search effort before they find a trading partner and a transaction takes place. The housing market also has well-established business cycle fluctuations. The observed large volatility in the time-to-sell is a clear indication that search frictions are a better description of the housing market than the Walrasian auctioner paradigm.

This paper studies a business cycle model of the housing market with search frictions and entry of both buyers and sellers to explain housing market dynamics. We focus on the following stylized facts, which are based on the empirical findings in Diaz and Jerez (2013). First, house prices are positively correlated with both sales and vacancies, and negatively correlated with time-to-sell. Second, sales, time-to-sell and vacancies are much more volatile than prices in the data. More specifically, the stylized facts are: (1) the elasticity of prices with respect to sales is $0.14 ;(2)$ the elasticity of prices with respect to time-to-sell is $-0.12 ;(3)$ the elasticity of prices with respect to vacancies is $0.06{ }^{1}$

We focus on these stylized facts because, combined, these elasticities determine the dynamics of vacancies, buyers, prices and market tightness - where market tightness is defined as the ratio of buyers to vacancies. These are the key variables in a search model of the housing market and are the equivalent of job vacancies, unemployment, market tightness and wages in the labor market, which are the central variables in search models of the labor market, see for example Pissarides (2000).

We show that the stylized facts imply that buyers and vacancies are positively correlated. ${ }^{2}$

\footnotetext{
${ }^{1}$ The vacancy quarterly data is from the Housing Vacancy Survey constructed by the US Census Bureau, from 1965:1 to 2010:4. Sales are measured using data from the National Association of Realtors (NAR) from 1968:1 to 2009:4. Time-to-sell data is collected from the American House Survey in the US Census Bureau from 1975:1 to 2010:4. See Diaz and Jerez (2013) for more details. The first two stylized facts have been extensively documented by a number of papers, see for example Genesove and Mayer (1997) and (2001), Glaeser and Gyourko (2006), Krainer (2001) and (2008), Ortalo-Magne and Rady (2006), Stein (1995) and the references therein. Although the third stylized fact has been less emphasized by the literature, Ngai and Sheedy (2015) also find that vacancies and prices are positively correlated using a different data source for vacancies, namely vacancy data from the NAR. Using the Case-Shiller Index or FHFA repeat sales prices for house prices give similar correlations. Finally, note that the stylized fact (3) implies that vacancies fluctuate more than sales and time-to-sell.

${ }^{2}$ We develop this more formally in section 3 , but this can be easily seen by looking at the stylized facts
} 
In other words, the empirical Beveridge Curve between buyers and vacancies is upward sloping in the housing market. By contrast, any search model à la Diamond-Mortensen-Pissarides (DMP) generates a downward sloping Beveridge Curve between vacancies and buyers. When vacancies become abundant, buyers find houses more quickly and the number of buyers drops, i.e. vacancies and buyers are negatively correlated. In the labor market, the same mechanism generates a downward sloping Beveridge Curve between vacancies and unemployment, which is consistent with labor market data, see Beveridge (1944) and Pissarides (2000).

To our knowledge the literature has not noted this important stylized fact. Given that the Beveridge Curve is downward sloping in baseline search models of the housing market à la DMP, these models are unable to match the sign of the cyclical behavior of vacancies, buyers, market tightness and prices, which are the key variables in a search model of the housing market - see for example Caplin and Leahy (2011), Diaz and Jerez (2013) and Ngai and Sheedy (2017) and Novy-Marx (2009). ${ }^{3}$

The assumption of both endogenous buyer and seller entry is what most distinguishes our paper from the existing literature on search and matching in the housing market. When sellers post more vacancies in the market, they make it easier for buyers to find a home. This raises the returns to search and incentivizes buyers to enter the market, which increases the number of buyers. This entry mechanism leads to an upward sloping Beveridge Curve between vacancies and buyers. As a result, the model is able to match the stylized facts qualitatively. We simulate the model with fluctuations in housing construction costs and the utility of being a homeowner. ${ }^{4}$ We show that the model is a substantial improvement compared to models that feature no endogenous entry of buyers. Beyond matching the signs of the correlations between the key variables, the model matches the elasticity of prices with respect to sales and time-to-sell

described earlier. An increase in vacancies raises prices, given the third stylized fact. From the second stylized fact, higher prices are associated with lower time-to-sell, or equivalently a higher market tightness. A higher market tightness makes it harder for buyers to find a home, so one can only match the positive correlation of prices and sales if the number of buyers increases. Therefore, vacancies and buyers move in the same direction.

${ }^{3} \mathrm{~A}$ positive correlation between buyers and vacancy (or unemployed and vacancies) with a downward sloping Beveridge Curve can happen only if market tightness barely fluctuates relative to fluctuations in the Beveridge Curve. This is what happens in Shimer (2005) with shocks to separations alone. In this case, the business cycle can be described as a movement along a fixed market tightness. Given that empirically there are sizable fluctuations in market tightness - time-to-sell, which is the inverse of the finding rate and depends on market tightness, varies as much as sales and much more than house prices-, it is not possible to match the two facts: a positive correlation between buyers and vacancy and fluctuations in market tightness.

${ }^{4}$ In section 6 we show that, as in Diaz and Jerez (2013) and Head, Lloyd-Ellis and Sun (2014) and (2016), we need movements in (at least) demand and supply to match the stylized facts. 
almost perfectly. The model also predicts an elasticity of prices with respect to vacancies that is relatively close to its empirical counterpart. Overall, the model performs well quantitatively and accounts for the stylized facts.

Related literature. The first paper to develop a model of the housing market with search frictions to study the relationship between prices and vacancy duration is the seminal work in Wheaton (1990). ${ }^{5}$ Subsequently, a number of papers have used a search and matching framework to study the housing market, which include Anenberg (2016), Burnside, Eichenbaum and Rebelo (2016), Caplin and Leahy (2011), Diaz and Jerez (2013), Genesove and Han (2012), Head et al. (2014) and (2016), Kashiwagi (2014a) and (2014b), Krainer (2001), Ngai and Tenreyro (2014), Ngai and Sheedy (2015) and (2017), Novy-Marx (2009), Piazzesi and Schneider (2009) and Smith (2015). With the exception of Diaz and Jerez (2013), these papers focus either on the steady state, predictable cycles such as hot and cold seasons, or long-run trends. Diaz and Jerez (2013) is the first paper to study a business cycle model of the housing market with search frictions. ${ }^{6}$

Our paper complements this previous work in two ways. First, we establish that the data imply a positive relationship between vacancies and buyers, i.e. that the Beveridge Curve in the housing market is upward sloping. Second, we propose an endogenous mechanism that can reproduce the positive correlation between buyers and vacancies. Given that the Beveridge Curve is downward sloping in standard DMP search models, it is not possible to match the sign of the co-movement of all the key variables, namely vacancies, buyers, market tightness and prices. ${ }^{7}$ Unlike papers in this literature, we assume an endogenous entry of both buyers and vacancies in a model with business cycle fluctuations. We show that this endogenous double entry is essential to generate an upward sloping Beveridge Curve. Finally, we show that the model is able to match the stylized facts qualitatively and quantitatively. ${ }^{8}$

\footnotetext{
${ }^{5}$ Arnott (1989) is also one of the first contributions that applied a search and matching framework to study the housing market, although his focus is on the vacancy rate in the rental market.

${ }^{6}$ Another main contribution of Diaz and Jerez (2013) is their empirical work on the business cycle statistics in the housing market, which we use to establish the stylized facts.

${ }^{7}$ In general, papers in the literature match the sign of the correlation either between prices and vacancies or between prices and sales, but not both. For example, in Caplin and Leahy (2011), Diaz and Jerez (2013) and Ngai and Sheedy (2015) the elasticity of prices with respect to vacancies is negative, whereas in Novy-Marx (2009) the elasticity of prices with respect to sales is negative, contrary to what we observe in the data. Although in Ngai and Sheedy (2015) the number of buyers and sellers are equal by construction, prices and vacancies are still negatively correlated because as sales increase, the stock of vacancies depletes. Essentially, vacancies are a state variable subject to a law of motion, and drops as more sales occur. As a result, a similar issue arises.

${ }^{8}$ To a lesser extent, our paper is also related to the literature that studies housing investment. Davis and
} 
We begin by studying the steady state to illustrate the mechanism in the model. Using comparative statics we explain why the model generates a positive correlation between buyers and vacancies, unlike baseline models. Next, we solve the model with business cycle fluctuations and simulate it. The final section reports the results and shows that the model can match the stylized facts qualitatively and quantitatively.

\section{The model in the steady state}

We begin with a description of the steady state equilibrium to show the intuition behind the model dynamics and how a positive Beveridge curve arises in this environment. The endogenous entry of buyers is a key ingredient to deliver an upward sloping Beveridge Curve and match the stylized facts. As in any model with entry, some cost or price must adjust to ensure an endogenous measure of buyers, otherwise the economy features an equilibrium where either every agent is a buyer or no one is. ${ }^{9}$ We implement this endogenous entry in the simplest way by assuming free entry and that search costs increase as more buyers enter the market. This gives us an endogenous entry of buyers and a mechanism through which buyers find it more attractive to enter the market as more vacancies are posted. ${ }^{10}$ When buyers' search costs are constant or decreasing in the measure of buyers, our model corresponds to a standard search model where in equilibrium all agents without a house are buyers. ${ }^{11}$ In this case the measure of buyers becomes a state variable and the Beveridge Curve is downward-sloping, as in the DMP model of the labor market.

Time is discrete. Agents are infinitively lived and discount future income with a discount factor $\beta$. The economy consists of households and a real estate sector with a representative

Heathcote (2005) is a notable reference in this literature, among others. See Piazzesi and Schneider (2016) and the references therein for a more detailed exposition of this big literature. However, compared to our paper and the literature above, these papers do not assume search frictions or study the behavior of time-to-sell and vacancies.

${ }^{9}$ For example, in the DMP model, expected vacancy costs increase as firms post more vacancies, or in some endogenous growth models the rate of return increases as more R\&D firms enter the market. An alternative and equivalent exposition is that as more agents enter the market, their value function decreases-for example, in our model the value of being a buyer decreases as more buyers enter, and similarly for the value of a vacancy in the DMP model.

${ }^{10}$ Quantitatively buyers expected search costs in the model vary in line with what we observe in data, as we discuss later on.

${ }^{11}$ This case is parallel to the DMP baseline model of the labor market, where all workers not holding a job search for jobs, i.e. are unemployed. The uninteresting equilibrium where no one searches may also exist depending on parameter values, just as in the baseline DMP model-implicitly in the DMP model parameters are assumed to satisfy that the value of unemployment is positive. 
realtor. All agents are risk-neutral. Households are either homeowners, buyers searching for a home or idle. Buyers must contact a realtor to purchase a home. Households wishing to sell their home must post a house vacancy on the market and search for a buyer. There is construction, so developers can build new housing if not enough existing homes are supplied by households. The cost of building a home is $k$. After the house is built, developers can post a vacancy on the market. We assume free entry in the market for houses and that newly built and existing houses are identical. As a result, the value of a house is $k$, regardless of whether it is newly built or old. ${ }^{12}$

To capture housing depreciation, at the beginning of the period a fraction $\delta$ of all houses, including vacancies, are destroyed. Further, there are search frictions in the housing market, meaning that it takes time for buyers to find a suitable house and for sellers to find a buyer. Similar to Diaz and Jerez (2013), Genesove and Han (2012), Head et al. (2014) and (2016), Novy-Marx (2009) and Wheaton (1990), among others, we model these search frictions with a matching function as in Pissarides (2000). The number of matches in a given period is given by a matching function $M(b,(1-\delta) v)$, where $b$ and $v$ are the measure of buyers and vacanciesgiven the timing of the model, only $(1-\delta) v$ vacancies are available at the beginning of the period. Assume that the matching function is concave, increasing in both of its arguments and displays constant returns to scale. Given this matching function, buyers find a suitable home with probability $m(\theta) \equiv M(b,(1-\delta) v) / b=M\left(1, \theta^{-1}\right)$, and sellers find buyers with probability $\theta m(\theta)=M(b,(1-\delta) v) /(1-\delta) v=M(\theta, 1)$, where $\theta$ denotes the housing market tightness and is given by the ratio of buyers to vacancies, i.e. $\theta \equiv b /(1-\delta) v$. Homeowners are mismatched with their house at an exogenous separation rate $s .{ }^{13}$ Upon separation, homeowners put their house on the market by posting a vacancy. ${ }^{14}$ Once the real estate investor finds a buyer for the

\footnotetext{
${ }^{12}$ Diaz and Jerez (2013) and Head et al. (2014) also have construction. Construction is stochastic and exogenous in Diaz and Jerez (2013), whereas it is endogenous in Head et al. (2014) and in our paper-it is determined by free entry. Developers do not play an important role in the model, other than supplying houses to the market when not enough houses become vacant.

${ }^{13}$ For example, they may need to move due to their jobs, may need a bigger home, and so on. See Ngai and Sheedy (2017) and Ngai and Tenreyro (2014) for search models of the housing markets where the separation rate is endogenous. However, in their models the contact rate is constant and independent of market tightness. An extension of this model with endogenous separations is left for future work.

${ }^{14}$ Alternatively, we could assume that the real estate sector acts as an intermediary in both purchases and sales, similar to Kashiwagi (2014a) and (2014b), and Gabrovski and Ortego-Marti (2018b). Given that in our model all houses are the same, whether they are newly built or existing homes, the value of a posted house is determined by the free entry condition, regardless of whether it is posted by a real estate firm or a household. Therefore, the results are unchanged. See Gabrovski and Ortego-Marti (2018a), a previous version of this paper,
} 
house, the buyer pays the price $p$.

As in Diaz and Jerez (2013), Ngai and Tenreyro (2014) and many other papers in the literature, we abstract from the rental vs selling decision and treat the rental market as a separate market. This is supported by Glaeser and Gyourko (2007), who find that there is no arbitrage between rental and owner occupied homes, mostly because both types of homes have very different characteristics; and Bachmann and Cooper (2014), who find that flows between owner and renter categories are mostly within each category, and from the rental market to the owner segment-i.e. entry is cyclical. By contrast, flows from the owner to the rental segment are virtually acyclical, and turnover is unrelated to vacancies in the rental market. This suggests that one can treat the rental segment as a different market.

\subsection{The housing market}

Let $H$ and $B$ denote the value functions of a homeowner and a buyer searching for a house. Households derive utility $\varepsilon$ when they own a house, whereas buyers searching for a house derive utility $\varepsilon^{B}$, with $\varepsilon^{B}<\varepsilon$. When a household wishes to become a buyer, the realtor takes on the task of finding a suitable home from the listing of available housing vacancies. This is a costly action for the real estate agent. Assume that the flow cost of servicing $b$ buyers is $\bar{c} b^{\gamma+1} /(\gamma+1)$. The realtor charges her customers a fee of $c^{B}$ in a competitive market, so her total revenue from providing services to buyers is $b c^{B}$. Profit maximization implies that in equilibrium $c^{B}(b)=\bar{c} b^{\gamma}$. This means that buyers incur flow $\operatorname{costs} c^{B}(b)$ while searching for houses, which are increasing in $b$. Intuitively, $c^{B}(b)$ includes search costs such as arranging and scheduling viewings, visiting houses or locating properties that match buyers' preferences or requirements. Although the buyer incurs some of these costs herself, for simplicity all these search costs are channeled through the realtor fee $c^{B}(b)$. These costs are increasing in the number of buyers to be serviced by the realtor, for example due to congestion externalities. ${ }^{15}$

\section{for this alternative version of the model.}

${ }^{15}$ Sirmans and Turnbull (1997) also use a similar convex cost function to model the provision of brokerage services by buyers' agents. In particular, the buyer's agent profits take the same form. Alternatively, we could model the participation/entry margin as in Garibaldi and Wasmer (2005), so that search costs $c^{B}$ are heterogenous among buyers. In this alternative framework, the (average) search cost increases as more buyers enter the market, as in our model. All that matters for our results is that the average search cost increases with the mass of buyers, not the exact mechanism, so the results are likely to be the same. Although the assumption in Garibaldi and Wasmer (2005) seems a more accurate description for labor markets, we prefer our interpretation of search costs in the housing market. In addition, it makes the business cycle exercise tractable. 
The assumption of increasing $\operatorname{costs} c^{B}(b)$ leads to an endogenous entry of buyers. Just as in any model with entry, there must be a cost or price that increases as more agents enter the market. For example, in the DMP model expected vacancy costs increase as more firms post vacancies, which leads to an endogenous measure of vacancies. The case of $c^{B}(b)$ constant or decreasing corresponds to the baseline search model with no entry of buyers. As the Bellman equations (1) and (3) show, if $c^{B}(b)$ is constant or decreasing either all agents enter the marketi.e. all households choose to be buyers - or no one does. This case corresponds to the usual DMP framework in the labor market where all non-employed workers search for jobs, i.e. are unemployed. With a constant or decreasing $c^{B}(b)$, the mass of buyers is a state variable subject to a law of motion similar to unemployment in the DMP model. This leads to a downward sloping Beveridge Curve. The results for the case with a constant or decreasing $c^{B}(b)$ are included in the third column of table 3 , section $6 .^{16}$

The Bellman equations for homeowners and buyers searching for a house are given by

$$
\begin{aligned}
& H=(1-\delta)\left[(1-s)(\varepsilon+\beta H)+s\left(\varepsilon^{B}+V+\beta B\right)\right]+\delta\left(\varepsilon^{B}+\beta B\right), \\
& B=-c^{B}(b)+m(\theta)(\varepsilon-p+\beta H)+(1-m(\theta))\left(\varepsilon^{B}+\beta B\right) .
\end{aligned}
$$

Equation (1) captures the dividends from owning a home. With probability $1-\delta$ the house is not destroyed. If there is no separation shock the homeowner receives a utility flow $\varepsilon$ and is a homeowner next period, which has present value $\beta H$. If there is a separation shock, the homeowner posts a vacancy to sell her house with value $V$. Additionally, she receives utility $\varepsilon^{B}$ and becomes a buyer searching for a house next period. ${ }^{17}$ If the house is destroyed, which

\footnotetext{
${ }^{16}$ Buyers pay flow costs $c^{B}(b)$ while they are searching for a house, so the overall cost buyers pay to the realtor is flow cost times the expected duration of search. Although the cost function $c^{B}(b)$ changes with the mass of buyers, so does the price. A common belief is that realtors charge a fixed percentage of the house price. However, a number of empirical papers find variation in realtor fees, see for example Barwick, Pathak and Wong (2017), Carney (1982), Frew, Jud and McIntosh (1993), Goolsby and Childs (1988), Han and Strange (2015), Schnare and Kulick (2009), Sirmans and Turnbull (1997) and Zietz and Newsome (2001). Given that search $\operatorname{costs} c^{B}(b)$ include other costs involved in house hunting, such as driving to visit houses, scheduling appointments after work, and so on, it is reasonable to assume that these costs increase with the number of buyers due to congestion externalities. Once we run the business cycle simulations, quantitatively the expected overall search costs as a fraction of the expected price vary little across states, and are quantitatively very close to the variation documented by the empirical literature - the results are available upon request. Overall, the predicted variation in costs as a fraction of house prices in the simulations is consistent with the empirical observations. We thank an anonymous referee for helpful comments and suggestions on the exposition and interpretation of these search costs.

${ }^{17}$ The household could choose to become idle after a separation or destruction shock. However, later on we
} 
happens with probability $\delta$, the household receives a flow payment $\varepsilon^{B}$ and becomes a buyer next period. Equation (2) captures that buyers searching for a home must pay flow $\operatorname{costs} c^{B}(b)$. The buyer finds a house with probability $m(\theta)$. After paying the price $p$ for the house, she enjoys utility $\varepsilon$ and is a homeowner next period. If the buyer does not find a house, she derives utility $\varepsilon^{B}$ and remains a buyer next period. Rearranging (2) delivers the following expression

$$
B=-c^{B}(b)+\varepsilon^{B}+\beta B+m(\theta)\left[\varepsilon-\varepsilon^{B}-p+\beta(H-B)\right] .
$$

Assume that there are flow costs associated with posting the vacancy, for example, for maintaining an ad online or holding open houses, which we denote $c^{R}$. The Bellman equation for a house vacancy is given by

$$
V=-c^{R}+(1-\delta)[(1-\theta m(\theta)) \beta V+\theta m(\theta) p] .
$$

The agent posting the vacancy pays a search $\operatorname{cost} c^{R}$ while she searches for a buyer. As long as the house is not destroyed, she finds a suitable buyer and receives the price of the house $p$ with probability $\theta m(\theta)$. Otherwise, she continues to hold a vacancy next period.

\subsection{Bargaining}

As is common in markets with search frictions, matching in the housing market leads to a surplus that must be shared among the buyer and the seller. As in Pissarides (2000), we assume that the house price $p$ is determined by Nash Bargaining as in Nash (1950) and Rubinstein (1982). Let $S^{B}$ and $S^{V}$ denote the surplus of the buyer and the seller posting a vacancy. If the house is sold, the buyer receives a value $\varepsilon-p+\beta H$ and the seller receives $p$. The outside options for the buyer and seller if the sale falls through are $\varepsilon^{B}+\beta B$ and $\beta V$ respectively. Therefore, the surpluses $S^{B}$ and $S^{V}$ are given by

$$
\begin{aligned}
& S^{B}=\varepsilon-\varepsilon^{B}-p+\beta(H-B), \\
& S^{V}=p-\beta V .
\end{aligned}
$$

assume free entry of buyers, which implies that $B=0$. We use this result already to simplify the exposition. 
The house price $p$ is the solution to the Nash Bargaining problem

$$
p=\underset{p}{\arg \max }\left(S^{V}\right)^{\eta}\left(S^{B}\right)^{1-\eta}
$$

where $\eta$ is the bargaining strength of the seller. The solution $p$ satisfies the first order condition

$$
\eta S^{B}=(1-\eta) S^{V}
$$

Intuitively, with Nash Bargaining both negotiating parties receive their outside option. In addition, the seller receives a share $\eta$ of the total surplus, whereas the buyer receives a share $1-\eta$.

\subsection{Equilibrium}

We assume that there is free entry of both buyers and seller, which ensures that $B=0$ and $V=k .{ }^{18}$ Given (4), free entry in the housing market gives the Housing Entry (HE) condition

$$
(\mathrm{HE}): \quad k=\frac{(1-\delta) \theta m(\theta) p-c^{R}}{1-\beta(1-\delta)(1-\theta m(\theta))} .
$$

Sellers enter the housing market until the cost of entering $k$ equals the expected net value from the house.

Similarly, free entry of buyers combined with (1) gives

$$
\frac{c^{B}(b)-\varepsilon^{B}}{m(\theta)}=\varepsilon-\varepsilon^{B}-p+\beta H=S^{B} .
$$

Buyers enter the market until the expected net cost of searching $\left(c^{B}(b)-\varepsilon^{B}\right) / m(\theta)$ equals the surplus from being a buyer $S^{B}$. Substitute the Nash Bargaining condition (8) and the surplus $S^{V}$ into the above equation to obtain the Buyer's Entry (BE) Condition

$$
(\mathrm{BE}): \quad \frac{c^{B}(b)-\varepsilon^{B}}{m(\theta)}=\left(\frac{1-\eta}{\eta}\right)(p-\beta k) .
$$

\footnotetext{
${ }^{18}$ Genesove and Han (2012) also assume that there is free entry of buyers - or alternatively, that there exists an infinite mass of potential buyers. However, they do not assume entry of sellers or vacancies. As a result, their free entry condition plays a role similar to a single free entry condition for sellers. As we shall see, double entry is key for the results and to match the empirical behavior of the housing market.
} 
Use the Bellman equation (1) to solve for $H$, which gives

$$
H=\frac{(1-\delta)(1-s) \varepsilon+[(1-\delta) s+\delta] \varepsilon^{B}+(1-\delta) s k}{1-\beta(1-\delta)(1-s)} .
$$

Substitute $H$ into $S^{B}$ and combine it with $S^{V}$ and the Nash Bargaining condition (8) to get the equilibrium price $p$. We denote this price rule the Price Equation (PP), which is given by

$$
(\mathrm{PP}): \quad p=\eta\left[\frac{\varepsilon-\varepsilon^{B}+\beta\left(\varepsilon^{B}+(1-\delta) s k\right)}{1-\beta(1-\delta)(1-s)}\right]+(1-\eta) \beta k .
$$

The equilibrium price is a weighted average between the present discounted value of net flows from owning a home and the value of the home.

The equilibrium is determined by the HE and BE entry conditions (9) and (11), and the price rule PP (13). Together, these form three equations in three unknowns $\{\theta, p, b\}$. It is easy to verify that an equilibrium with buyers and vacancies exists and is unique. ${ }^{19}$ Intuitively, (13) determines the equilibrium price $p^{*}$. Given $p^{*}$, the equilibrium tightness $\theta^{*}$ is determined by the HE condition. Given $p^{*}$ and $\theta^{*}$, the equilibrium $b^{*}$ adjusts to satisfy the BE condition. Overall, entry of houses for sale pins down the equilibrium market tightness for houses $\theta^{*}$. Given equilibrium $\theta^{*}, b^{*}$ adjusts to make sure that the cost of searching for a house equals the future stream of dividends from owning a home.

Figure 1a shows the PP and HE conditions in the $(\theta, p)$ space. The PP curve is a horizontal line, whereas the HE condition describes a downward sloping relationship between $p$ and $\theta$ - the right-hand-side of the $\mathrm{HE}$ condition is increasing in both $\theta$ and in $p$. Intuitively, an increase in the price $p$ makes posting a vacancy more profitable. This leads to more entry in the housing market and lowers tightness $\theta$. Combined, the PP and HE conditions determine the unique equilibrium price and tightness $p^{*}$ and $\theta^{*} \cdot{ }^{20}$

Given equilibrium price and tightness $p^{*}$ and $\theta^{*}$, there exists a unique $b^{*}$ that satisfies the $\mathrm{BE}$ condition. ${ }^{21}$ The equilibrium $\theta^{*}$ defines the slope of a line through the origin in the $(b, v)$

\footnotetext{
${ }^{19}$ The uninteresting case with no vacancies, buyers or entry $v=b=0$ is also an equilibrium.

${ }^{20}$ The intercept is guaranteed if $p^{*}=\eta\left[\frac{\varepsilon-\varepsilon^{B}+\beta\left(\varepsilon^{B}+(1-\delta) s k\right)}{1-\beta(1-\delta)(1-s)}\right]+(1-\eta) \beta k>\frac{k+c^{R}}{1-\delta}$. We assume that the parameters satisfy this condition.

${ }^{21}$ Rearranging the BE condition gives $\frac{c^{B}(b)-\varepsilon^{B}}{\left(\frac{1-\eta}{\eta}\right)\left(p^{*}-\beta k\right)}=m\left(\theta^{*}\right)$. The left-hand side is strictly increasing in $b$ from 0 to infinity given equilibrium price and tightness $p^{*}$ and $\theta^{*}$.
} 


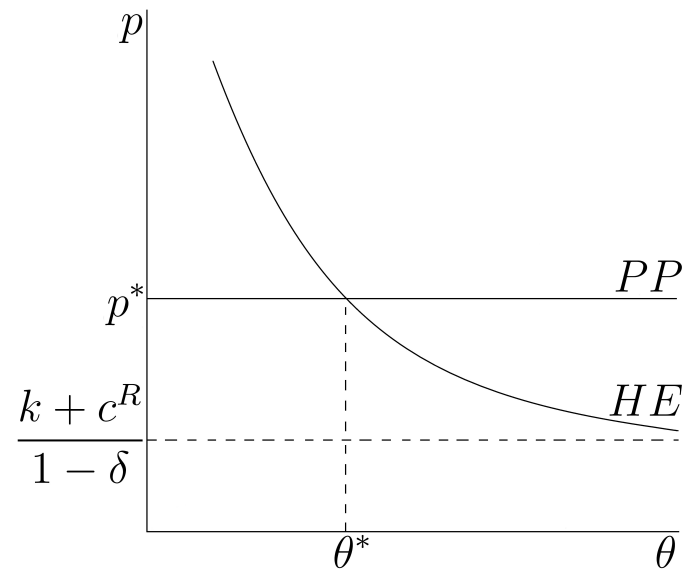

(a) Equilibrium price $p^{*}$ and market tightness $\theta^{*}$

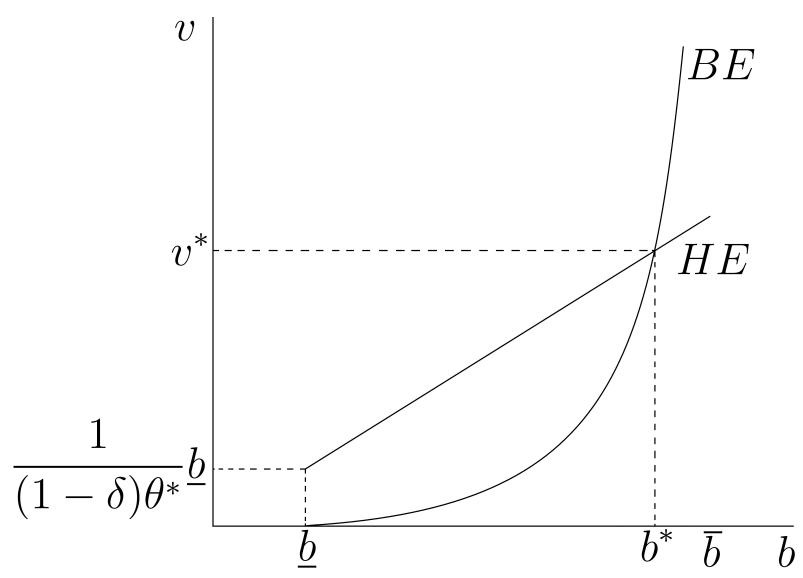

(b) Equilibrium buyers $b^{*}$ and vacancies $v^{*}$

\section{Figure 1: Equilibrium in the housing market}

Note: Figure 1 a depicts the house entry condition (HE) from (9) and the price relationship (PP) from (13), which determine the equilibrium price $p^{*}$ and market tightness $\theta^{*}=b^{*} /\left[(1-\delta) v^{*}\right]$. The (HE) condition captures that an increase in house prices makes posting a vacancy more profitable, which leads to a larger entry of sellers and a lower tightness. The (PP) condition is determined by Nash Bargaining between the buyer and the seller. In figure 1b, the (HE) condition is obtained from the equilibrium market tightness in Figure 1a, which describes a straight line with a slope proportional to the equilibrium market tightness. The (BE) curve in figure $1 b$ depicts the buyers entry condition (11). According to the (BE) condition, an increase in the ratio of vacancies to buyers makes it easier for buyers to find a house and leads to an increase in the entry of buyers. The (BE) curve is the equivalent of the Beveridge Curve in DMP models of the labor market and is upwards sloping due to buyers entry.

space. To keep the exposition similar to Pissarides (2000), we also denote this line through the origin as the HE curve. Figure $1 \mathrm{~b}$ represents the $\mathrm{HE}$ and BE curves in the $(b, v)$ space, which determine the equilibrium vacancies and buyers $v^{*}$ and $b^{*}$. Let $\underline{b}$ satisfy $c^{B}(\underline{b})-\varepsilon^{B}=0$ and $\bar{b}$ satisfy $\eta\left(c^{B}(\bar{b})-\varepsilon^{B}\right) /[(1-\eta)(p-\beta k)]=1$. The BE condition (11) defines an upward sloping relationship between buyers and vacancies in the interval $[\underline{b}, \bar{b}]$. Intuitively, the cost of searching increases with buyers $b$. To enter the market, buyers must be compensated with a higher finding probability $m(\theta)$, i.e. with a lower $\theta$ and a higher $v$. This can be proven formally by totally differentiating the BE condition. The slope of the BE condition is positive and given by

$$
\frac{d v}{d b}=\frac{v}{b}\left[1+\frac{\gamma}{\alpha} \cdot \frac{c^{B}(b)}{c^{B}(b)-\varepsilon^{B}}\right]
$$

where $\alpha$ denotes the elasticity of $m(\theta)$ with respect to $\theta$, i.e. $\alpha=-m^{\prime}(\theta) \cdot \theta / m(\theta)$.

As $b$ approaches $\bar{b}, m(\theta)$ approaches 1 to satisfy the BE condition. This implies that $\theta$ tends to 0 and $v$ tends to infinity - the slope of the cord from the origin to the BE curve is $1 /[\theta(1-\delta)]$. Similarly, as $b$ tends to $\underline{b}, m(\theta)$ tends to zero along the BE curve and as a result $v$ approaches 0 , since $b \geq \underline{b}>0$. Values $0<b<\underline{b}$ are not an equilibrium, since in that region $B$ is strictly 
positive, given that the surplus $S^{B}$ and $\varepsilon^{B}-c^{B}(b)$ are both positive. A positive value of being a buyer drives entry, which increases $b$. This proves the existence of a unique equilibrium with positive buyers and vacancies. ${ }^{22}$

\subsection{Comparative statics}

In section 4 we introduce business cycle fluctuations driven by demand and supply shocks. As Diaz and Jerez (2013) and Head et al. (2014) and (2016) show, one needs at least both demand and supply shocks to have a shot at replicating the key facts in the housing market. ${ }^{23}$ To provide some intuition for the mechanism in the business cycle version of the model, this section describes the effect of a demand and supply shock separately on the steady state equilibrium.

We view a demand shock as an increase in $\varepsilon$ and $\varepsilon^{B}$ that raises $\varepsilon-\varepsilon^{B}$, i.e. we assume that $\varepsilon$ and $\varepsilon^{B}$ move in the same direction, but that $\varepsilon$ fluctuates more than $\varepsilon^{B}$. Intuitively, a positive demand shock raises the utility flow of owning a house $\varepsilon$ more than the outside option $\varepsilon^{B}$, making owning a home more desirable. ${ }^{24}$ A supply shock corresponds to an increase in $k$. This section also illustrates how in response to each shock both vacancies and buyers move in the same direction. This co-movement of vacancies and buyers allows the model to match the stylized facts once both shocks are combined in the calibration.

Consider first the case where both $\varepsilon$ and $\varepsilon^{B}$ increase, but with an increase in the net utility derived from being a homeowner $\varepsilon-\varepsilon^{B}$. This corresponds to a demand shock, since owning a home yields a higher utility. Figure 2 shows the effect graphically. In panel A, an increase in $\varepsilon-\varepsilon^{B}$ shifts the PP curve upward while leaving the HE curve unchanged. This raises the equilibrium price and lowers the equilibrium market tightness. Intuitively, a higher net utility from homeownership increases the surplus and raises prices because of bargaining. Higher house prices increase the entry of sellers and lower market tightness - or alternatively, sellers post more

\footnotetext{
${ }^{22}$ To simplify the exposition of the equilibrium and the comparative statics exercise, we focus on the housing market tightness $\theta$. The effect on time-to-sell is uniquely determined by market tightness $\theta$-it is inversely related to market tightness $\theta$.

${ }^{23}$ To match the stylized facts, the dynamic model with business cycle in section 4 calibrates the model using a mix of both supply and demand shocks, similar to Diaz and Jerez (2013), Head et al. (2014) and (2016), Ngai and Sheedy (2017) or Novy-Marx (2009). In addition, Diaz and Jerez (2013) add a shock to separations. See the discussion in section 4 .

${ }^{24}$ In particular, this includes the case with a fixed $\varepsilon^{B}$ and an increase in $\varepsilon$. This is more general than the usual demand shock in the literature, which corresponds to $\varepsilon^{B}=0$, i.e. only $\varepsilon$ fluctuates. The quantitative results barely change if we set $\varepsilon^{B}$ equal to 0 and let $\varepsilon$ fluctuate. We do not consider the case where $\varepsilon$ and $\varepsilon^{B}$ move in opposite directions.
} 


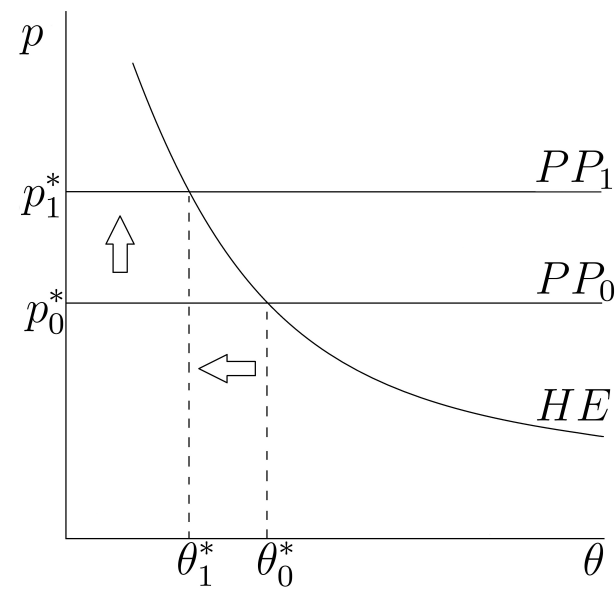

(a) Response of equilibrium price $p^{*}$ and market tightness $\theta^{*}$ to a utility shock

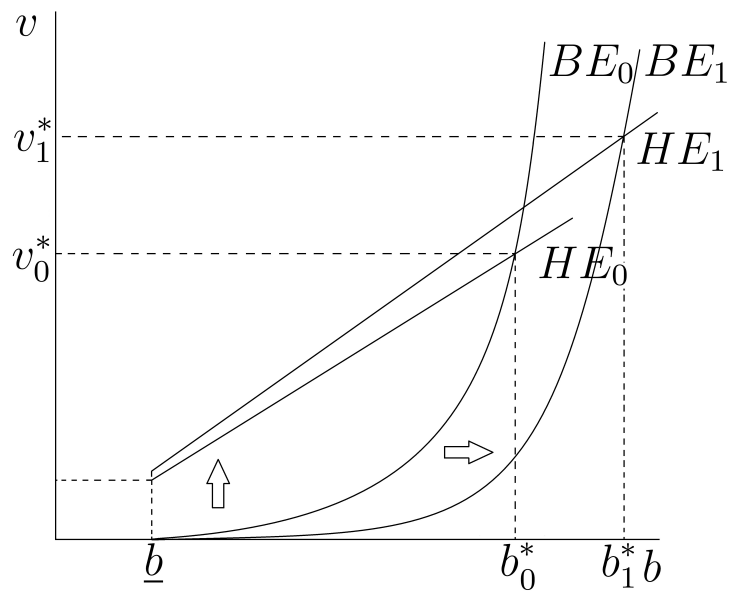

(b) Response of equilibrium buyers $b^{*}$ and vacancies $v^{*}$ to a utility shock

\section{Figure 2: Comparative Statics with a Utility (Demand) Shock}

Note: The figure shows the effect of an increase in both utility flows $\varepsilon$ and $\varepsilon^{B}$ that raises the net utility of owning a home $\varepsilon-\varepsilon^{B}$. The first panel shows that the demand shock raises prices due to a higher surplus from matching, and lowers market tightness due to entry of sellers. The second panel shows that both buyers and vacancies increase due to entry of buyers.

vacancies for any given number of buyers. Sellers are willing to tolerate a lower probability of selling a vacant house because they are compensated with a higher price. Panel B shows the effect on buyers and vacancies. The lower equilibrium tightness rotates the HE curve to the left, i.e. the slope is steeper. An increase in both $p$ and $m(\theta)$ raise $b$ for any vacancy level, so the BE curve shifts right. Overall, vacancies and buyers $v$ and $b$ both increase. Intuitively, a lower market tightness makes it easier for buyers to find a house, which drives buyers entry.

Figure 3 shows the effect of an increase in construction costs $k$. In panel A, both the PP and HE curves shift up - the right-hand-side of the HE curve is increasing in $\theta$. Although the effect on market tightness might seem ambiguous, substituting the PP price rule into the HE condition shows that market tightness increases. ${ }^{25}$ Intuitively, when costs $k$ increase sellers must be compensated with a lower waiting time to ensure entry, so market tightness $\theta$ increases. Alternatively, for a given number of buyers, fewer sellers enter the housing market and the number of vacancies drop, so market tightness increases. Panel B shows the effect on buyers and vacancies. The HE curve becomes flatter due to the increase in market tightness.

${ }^{25}$ Substituting $p$ into the HE condition gives

$$
k=\frac{(1-\delta) \theta m(\theta)}{1-\beta(1-\delta)(1-\theta m(\theta))}\left[\eta \frac{(1-\delta) s}{1-\beta(1-\delta)(1-s)}+1-\eta\right] \beta k+\eta \frac{(1-\delta) \theta m(\theta)\left[\frac{\varepsilon-(1-\beta) \varepsilon^{B}}{1-\beta(1-\delta)(1-s)}\right]-c^{R}}{1-\beta(1-\delta)(1-\theta m(\theta))}
$$

Using the above expression it readily follows that $\theta$ increases when $k$ goes up. 


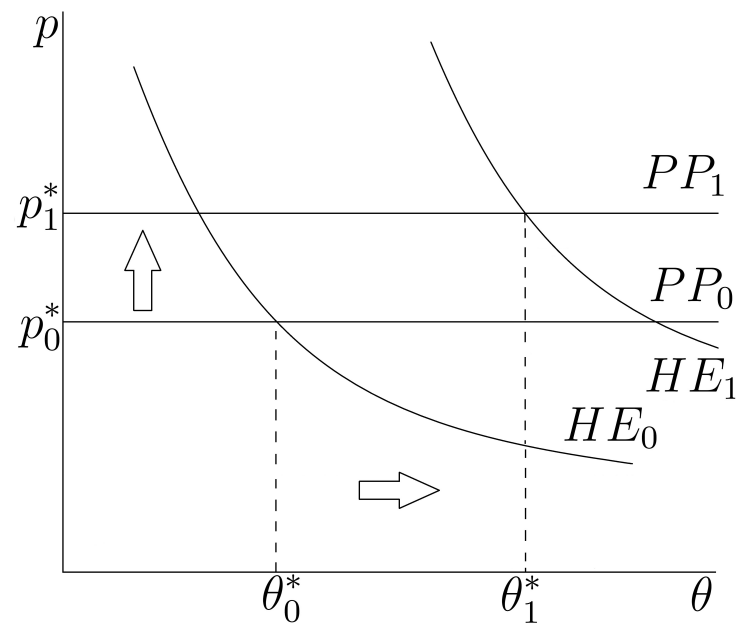

(a) Response of equilibrium price $p^{*}$ and market tightness $\theta^{*}$ to a construction shock

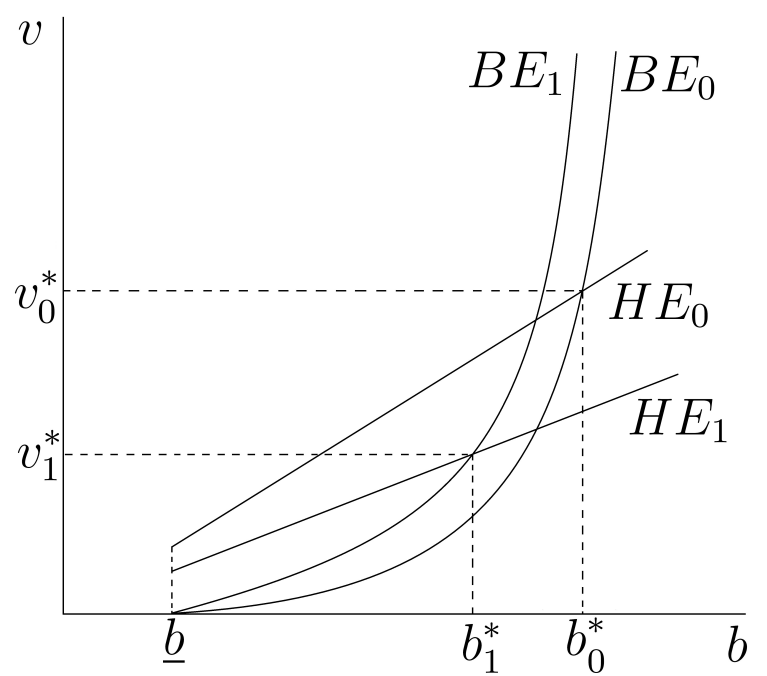

(b) Response of equilibrium buyers $b^{*}$ and vacancies $v^{*}$ to a construction shock

Figure 3: Comparative Statics with a Construction Cost (Supply) Shock

Note: The figure shows the effect of an increase in construction costs $k$. The first panel shows that the supply shock raises prices due to increasing costs, but raises tightness as fewer sellers enter the market. The second panel shows a drop in both buyers and vacancies. Fewer buyers enter the market as it becomes increasingly difficult to find a home when tightness increases.

Given the increase in $\theta$, and given that $p-\beta k$ is decreasing in $k$, the BE curve shifts left. ${ }^{26}$ This leads to lower vacancies and buyers $v$ and $b$. Intuitively, the increase in market tightness reduces the buyer's surplus and their incentives to enter the housing market.

\section{The Beveridge Curve and the importance of buyers entry}

In baseline DMP search models of the labor market, vacancies and unemployment describe a downward sloping curve known as the Beveridge Curve. Intuitively, when firms post more job vacancies, unemployed workers find jobs more easily. As a result, unemployment decreases. This mechanism is inherent to any search model in which unemployment is essentially a state variable subject to a law of motion. Because there is no entry of workers from out of the labor force in the baseline model, vacancies and unemployment are negatively correlated. Empirically, this negative relationship between vacancies and unemployment is a well established stylized

${ }^{26}$ Solving for the price from the PP rule and the HE condition gives

$$
p-\beta k=-\eta \beta\left\{\frac{1-(1-\delta)[s(1-\beta)+\beta]}{1-\beta(1-\delta)(1-s)}\right\} k+\eta \frac{\varepsilon-(1-\beta) \varepsilon^{B}}{1-\beta(1-\delta)(1-s)} .
$$


fact since Beveridge (1944). The issue in search models of the housing market is that the stylized facts imply that the measure of buyers and vacancies - the equivalent of unemployment and vacancies - are positively correlated, i.e. the Beveridge Curve must be upward sloping.

Although we prove this formally below, a simple inspection of the stylized facts illustrates why vacancies and buyers are positively correlated. The elasticity of vacancies and sales with respect to prices are both positive, whereas the elasticity of time-to-sell with respect to prices is negative. The elasticities are reported in the first column of table 3. When prices increase, given the empirical elasticities vacancies and tightness both increase (time-to-sell decreases). Given that sales equal $b m(\theta)$ and that $m(\theta)$ is lower, the elasticity of prices with respect to sales can only be positive if the measure of buyers $b$ increases sufficiently. Overall, vacancies and buyers both increase and are positively correlated.

The intuition for why a search model of the housing market without buyers entry generates a counterfactual Beveridge Curve is the following. Given that the elasticity to time-to-sell is negative, a shock that raises prices must also raise market tightness so that the time-to-sell $1 /(\theta m(\theta))$ decreases. However, if market tightness increases, vacancies are sold faster. Vacancies decrease, which leads to a negative correlation between vacancies and prices, contrary to what we observe in the data. Alternatively, if the measure of buyers is determined by a law of motion, an increase in tightness implies that sellers are posting fewer house vacancies. With fewer vacancies, buyers take longer to find a home, so the measure of buyers increases. Again, buyers and vacancies are negatively correlated (i.e. the Beveridge Curve is downward sloping), contrary to what we observe in the data.

To show more formally that the data imply an upward sloping Beveridge Curve, note that the sign of the elasticity of prices with respect to time-to-sell and vacancies are $d \log (p) / d \log [1 /(\theta m(\theta))]<$ 0 and $d \log (p) / d \log (v)>0$, which imply that $d \log [1 /(\theta m(\theta))] / d \log (v)<0$. After some derivations the latter elasticity can be expressed as

$$
\frac{d \log \left(\frac{1}{\theta m(\theta)}\right)}{d \log (v)}=-(1-\eta) \frac{d \theta}{d v} \frac{v}{\theta}
$$

where $1-\eta$ is the elasticity of $\theta m(\theta)$, i.e. $1-\eta=[d(\theta m(\theta)) / d \theta] \cdot[\theta /(\theta m(\theta))]$. Given that $d \log [1 /(\theta m(\theta))] / d \log (v)<0$, this implies that $[d \theta / d v] \cdot[v / \theta]>0$. Log-differentiate market tightness to get $(d b / d v) \cdot(v / b)=1+(d \theta / d v) \cdot(v / \theta)$, which is positive given that $(d \theta / d v) \cdot(v / \theta)>$ 
0. As a result $d v / d b$ is positive, given the stylized facts. In other words, the data is consistent with an upward sloping Beveridge Curve. As a result, any search model of the housing market that incorporates the usual dynamics of search and matching models will struggle to derive a positive Beveridge Curve between buyers and vacancies. For this reason, papers in the literature struggle to match the signs of the correlations in the stylized facts. ${ }^{27}$

Entry changes the sign of the relationship between buyers and vacancies. When sellers post more vacancies, market tightness decreases and makes it easier for buyers to find homes. This incentivizes buyers to enter the market and increases the measure of buyers. This leads to an upward sloping Beveridge Curve - the BE curve in our model. Due to this upward sloping curve, changes in the utility of homeownership and changes in costs move vacancies and buyers in the same direction, as section 2.4 shows using comparative statics. As we see in the next section, this enables our model to match the stylized facts. ${ }^{28}$

\footnotetext{
${ }^{27}$ Of course, one could find a positive correlation between vacancies and unemployment even in the DMP model with a downward sloping Beveridge Curve. If tightness barely moves during the cycle and fluctuations come mostly from shifts in the Beveridge Curve, we would also observe a positive correlation between unemployment and vacancies - see for example the case in Shimer (2005) of stochastic shocks to separations. However, if tightness fluctuates significantly, as is the case both in the labor market and in the housing market, the dynamics of the model describe movements along the BC and deliver a negative correlation between unemployment and vacancies. Hence the difficulty in matching the sign of the co-movements in the key variables all at once.

${ }^{28}$ The comovement of prices, sales, time-to-sell and vacancies in the stylized facts have been reported by a number of studies, see for example Diaz and Jerez (2013), Genesove and Mayer (1997) and (2001), Glaeser and Gyourko (2006), Krainer (2001) and (2008), Ngai and Sheedy (2015), Ortalo-Magne and Rady (2006), Stein (1995) and the references therein. A positive Beveridge Curve is broadly consistent with the results in Bachmann and Cooper (2014) who find that in booms households are more likely to move into the owner occupied segment, suggesting entry of buyers in expansions, whereas the own to rent flows are essentially acyclical. Our results are also broadly consistent with Hsieh and Moretti (2003), who find that as prices increase, time-to-buy increases and time-to-sell decreases. However, a direct test of the slope of the Beveridge Curve is unavailable due to lack of data. Unlike labor markets, no good measure of buyers or "searchers" is available for the housing market. Given the importance of unemployment for both measuring economic activity and the provision of government programs such as unemployment insurance, data sets have been developed with detailed information on the methods used to search for jobs and on the intensity of job search. As a result, relative to the housing market, we have a good idea of who an "unemployed" worker is, i.e. there are good measures of the number or unemployed or "searchers". Unfortunately, there is no similar data that allows us to measure buyers or house "searchers" in the same way we can measure unemployment in the labor market. To measure buyers, we would need to ask households who do not own a house on both the desire to own a house and on the intensity and methods of house search. To stress the difficulties in obtaining a reliable measure of buyers, even when data on the method and intensity of job search are available, the issue of measurement of unemployment and when should a worker be counted as unemployed (i.e. searching) is still controversial - e.g., definitions vary across countries and across time. On these measurement issues see among others Flinn and Heckman (1983), Hall (1970), and Jones and Riddell (1999) and (2006). We thank an anonymous referee for helpful comments and suggestions on this issue.
} 


\section{Housing market with business cycles}

The model easily generalizes to an environment with business cycle fluctuations. As we show in the steady state version of the model in section 2, the endogenous entry of buyers provides a mechanism that delivers an upward sloping Beveridge Curve, thus allowing the model to match the stylized facts qualitatively. In this section we introduce business cycles to show that the model is also able to match the stylized facts quantitatively. As discussed earlier, both supply and demand shocks are required to match the stylized facts qualitatively, so the quantitative exercise combines both sources of shocks - see Diaz and Jerez (2013) and Head et al. (2014) and (2016).

We follow the literature on search and matching in the labor market and assume that aggregate fluctuations are driven by a single shock. In our model, the aggregate state of the economy is driven by changes in the homeowner's net utility $\varepsilon-\varepsilon^{B}$, where higher net utility is associated with a housing boom. Furthermore, we allow construction costs $k$ to vary along the cycle as well. ${ }^{29}$ The exogenously imposed variation of $k$ captures in a simple and tractable way the intuition that more housing construction is associated with higher construction costs. ${ }^{30}$ Our assumption that $\varepsilon-\varepsilon^{B}$ and $k$ both vary and are perfectly correlated along the business cycle is analogous to the assumption in Shimer (2005), where shocks to labor productivity affect the endogenous separation rate, but for simplicity he models the changes in the separation rate as exogenous. The intuition for the mechanism in the model with business cycles is the same as in the steady state version described in section 2 .

Let $i$ and $i^{\prime}$ denote the state of the economy and next period's state. In addition, let $X_{i}$ and $\mathbb{E}_{i} X_{i^{\prime}}$ denote the value function $X$ in state $i$ and its expectation over future states $i^{\prime}$, conditional on state $i$. State $i$ captures both the value of $\varepsilon_{i}-\varepsilon_{i}^{B}$ and the value of $k_{i}$, so both shocks are perfectly correlated. This is similar to Shimer (2005), where an underlying state determines both labor productivity and separations. As in his paper, our calibration of the processes for $\varepsilon_{i}-\varepsilon_{i}^{B}$ and $k_{i}$ determines the correlation between the two shocks.

\footnotetext{
${ }^{29}$ In our model, changes in utility can be interpreted as a demand shock and changes in construction costs as a perfectly correlated supply shock. Diaz and Jerez (2013) have three different shocks, a demand and supply shock similar to the ones in the model, and in addition a separation shock. Head et al. (2014) and (2016) also have demand and supply shocks. As Diaz and Jerez (2013) show, a simple search and matching model with either a supply or a demand shock alone cannot match the business cycle movements in the housing markets.

${ }^{30}$ For example, more construction increases the price of materials, land, and labor required to build a house.
} 
The Bellman equations are given by

$$
\begin{aligned}
& H_{i}=(1-\delta)(1-s)\left(\varepsilon_{i}+\beta \mathbb{E}_{i} H_{i^{\prime}}\right)+\delta\left(\varepsilon_{i}^{B}+\beta \mathbb{E}_{i} B_{i^{\prime}}\right)+(1-\delta) s\left[\varepsilon_{i}^{B}+\beta \mathbb{E}_{i} B_{i^{\prime}}+V_{i}\right], \\
& B_{i}=-c^{B}\left(b_{i}\right)+\varepsilon_{i}^{B}+\beta \mathbb{E}_{i} B_{i^{\prime}}+m\left(\theta_{i}\right)\left[\varepsilon_{i}-\varepsilon_{i}^{B}-p_{i}+\beta \mathbb{E}_{i}\left(H_{i^{\prime}}-B_{i^{\prime}}\right)\right], \\
& V_{i}=-c^{R}+(1-\delta)\left[\left(1-\theta_{i} m\left(\theta_{i}\right)\right) \beta \mathbb{E}_{i} V_{i^{\prime}}+\theta_{i} m\left(\theta_{i}\right) p_{i}\right] .
\end{aligned}
$$

The solution to the model follows similar steps as in section 2. The house price $p_{i}$ is determined by Nash Bargaining, which delivers the sharing rule

$$
\eta S_{i}^{B}=(1-\eta) S_{i}^{V}
$$

where the surplus of the buyer and the seller are $S_{i}^{B}=\varepsilon_{i}-\varepsilon_{i}^{B}-p_{i}+\beta\left(\mathbb{E}_{i} H_{i^{\prime}}-\mathbb{E}_{i} B_{i^{\prime}}\right)$ and $S_{i}^{V}=p_{i}-\beta \mathbb{E}_{i} V_{i^{\prime}}$. Free entry of buyers and vacancies imply $B_{i}=0$ and $V_{i}=k_{i}$ and, as a result, $\mathbb{E}_{i} B_{i^{\prime}}=0$ and $\mathbb{E}_{i} V_{i^{\prime}}=\mathbb{E}_{i} k_{i^{\prime}}$. Combining (16) with the Nash Bargaining condition (18) and free entry gives the Buyer Entry (BE) condition

$$
(\mathrm{BE}): \quad \frac{c^{B}\left(b_{i}\right)-\varepsilon_{i}^{B}}{m\left(\theta_{i}\right)}=\left(\frac{1-\eta}{\eta}\right)\left(p_{i}-\beta \mathbb{E}_{i} k_{i^{\prime}}\right)
$$

Free entry of vacancies $V_{i}=k_{i}$ together with (17) gives the Housing Entry (HE) condition

$$
(\mathrm{HE}): \quad k_{i}+c^{R}=(1-\delta)\left[\left(1-\theta_{i} m\left(\theta_{i}\right)\right) \beta \mathbb{E}_{i} k_{i^{\prime}}+\theta_{i} m\left(\theta_{i}\right) p_{i}\right]
$$

The Bellman equation for homeowners (15) can be re-written as

$$
H_{i}=(1-\delta)(1-s)\left(\varepsilon_{i}-\varepsilon_{i}^{R}+\beta \mathbb{E}_{i} H_{i^{\prime}}\right)+\varepsilon_{i}^{R}+(1-\delta) s k_{i}
$$

Using the Nash Bargaining condition (18) gives the Price (PP) rule

$$
(\mathrm{PP}): \quad p_{i}=\eta\left(\varepsilon_{i}-\varepsilon_{i}^{B}+\beta \mathbb{E}_{i} H_{i^{\prime}}\right)+(1-\eta) \beta \mathbb{E}_{i} k_{i^{\prime}}
$$

Let $N$ denote the number of states $i$. The equilibrium consists of a system with $4 N$ unknowns $\left\{\theta_{i}, p_{i}, b_{i}, H_{i}\right\}_{i}$ and $4 N$ equations, namely for each state $i$ the BE condition (19), the 
HE condition (20), the PP rule (22) and the Bellman equation for $H_{i}(21)$. The equilibrium can be reduced to a linear system of equations that can be easily solved numerically. ${ }^{31}$

\section{Calibration}

We calibrate the model at a quarterly frequency. Following Ngai and Tenreyro (2014), the discount factor $\beta$ matches an annual interest rate of $6 \%$. As in Ngai and Tenreyro (2014), the bargaining power $\eta$ is set to 0.5. Van Nieuwerburgh and Weill (2010) report an annual destruction rate of $1.6 \%$, which implies $\delta=0.004$. We set $s$ equal to 0.024 so the average tenure is 9 years, as in Diaz and Jerez (2013). We impose a standard Cobb-Douglas matching function $m(\theta)=\min \left\{\mu \theta^{-\alpha}, 1\right\}$. Given our calibration, in our simulations the equilibrium tightness always implies a probability strictly lower than 1 . We set $\alpha=0.16$, which is the estimate in Genesove and Han (2012). To calibrate the matching efficiency parameter $\mu$ we draw from estimates of the expected time-to-sell and time-to-buy. For the time-to-sell, we follow Ngai and Sheedy (2017) and take the mid point between the average vacancy duration from the American Housing Survey and the Census Bureau. ${ }^{32}$ This gives 6.1 months, so the expected vacancy duration is 2 quarters. Genesove and Han (2012) report that time-to-sell and time-to-buy are very close, so we set the expected length of time a buyer is on the market to 2 quarters as well. Together these two moments yield that $\mu$ equals 0.5 and that the average market tightness is 1.006. This estimate of the market tightness together with the normalization that the average measure of buyers is 1 , i.e. $\mathbb{E} b_{i}=1$, pins down the search cost for the investor, $c^{R}=0.564$, and the expected construction cost, $\mathbb{E} \ln \left(k_{i}\right)=3.854$. We follow Ghent (2012) and set the transaction cost of the buyer to be $8 \%$ of the home value. This yields that $\bar{c}$ equals 2.117 .

As we discussed in section 4, a single aggregate shock induces fluctuations in both the homeowner's net utility $\varepsilon-\varepsilon^{B}$ and the construction cost $k$. To simplify the simulations, as in Shimer (2005) we assume that a single underlying stochastic process determines both demand

\footnotetext{
${ }^{31}$ More specifically, the Bellman equations for $H_{i}(21)$ define a system of linear equations that give equilibrium $H_{i}^{*}$. Given equilibrium $H_{i}^{*}$, the PP rule (22) gives the equilibrium price $p_{i}^{*}$. Given $p_{i}^{*}$, the HE condition (20) for each $i$ define a system of linear equations in $\theta_{i} m\left(\theta_{i}\right)$ if we treat $\theta_{i} m\left(\theta_{i}\right)$ as a variable. The equilibrium $\theta_{i} m\left(\theta_{i}\right)$ then determines the unique equilibrium tightness $\theta_{i}^{*}$. Finally, the $\mathrm{BE}$ condition gives equilibrium buyers $b_{i}^{*}$. The equilibrium vacancies are then determined using the equilibrium tightness and noting that $v_{i}=b_{i} /\left[(1-\delta) \theta_{i}\right]$.

${ }^{32}$ For the period of $2001-2005$, the American Housing Survey reports a mean vacancy duration of $7-8$ months - see Ngai and Sheedy (2017). The Census Bureau reports that the average of the median number of months for a newly constructed vacancy between $1974: 12-2011: 11$ is 5.2 months.
} 
$\left(\varepsilon-\varepsilon^{B}\right)$ and supply $(k)$ shocks, so the two shocks are perfectly correlated. ${ }^{33}$ As in his model, the calibration of both stochastic processes determines the correlation between both shocks. During a boom the economy experiences a demand shock that raises the net utility of being a homeowner $\varepsilon-\varepsilon^{B}{ }^{34}$ This higher demand is associated with increasing construction costs $k$. Intuitively, high demand for housing increases the demand for labor and inputs used in construction, which ultimately increases construction costs. Overall, as in Diaz and Jerez (2013) supply and demand shocks are negatively correlated.

More specifically, we model $\ln (\varepsilon), \ln \left(\varepsilon^{B}\right)$, and $\ln (k)$ as $\mathrm{AR}(1)$ processes driven by the same underlying shock $u_{t}$. In particular, the $\operatorname{AR}(1)$ processes are

$$
\begin{aligned}
& \ln \left(\varepsilon_{t}\right)=\zeta_{\varepsilon}+\rho \ln \left(\varepsilon_{t-1}\right)+u_{t} \\
& \ln \left(\varepsilon_{t}^{B}\right)=\zeta_{\varepsilon^{B}}+\rho \ln \left(\varepsilon_{t-1}^{B}\right)+u_{t} \\
& \ln \left(k_{t}\right)=\zeta_{k}+\rho \ln \left(k_{t-1}\right)+a u_{t}
\end{aligned}
$$

The impact of the shock on both $\ln \left(\varepsilon_{t}\right)$ and $\ln \left(\varepsilon_{t}^{B}\right)$ is the same. Intuitively, this implies that the utility for home owners and renters increases in the same proportion. Alternatively, we could just express it as a process for $\varepsilon-\varepsilon^{B}$. As reported in Diaz and Jerez (2013), the standard deviation of the Case-Shiller price index for the period $1987: 1-2010: 4$ is $4.1 \%$. The standard deviation of the shock $\sigma_{u}$ equals 0.1429 to match the standard deviation of house prices in the data. We set a equal to 0.218 to match the elasticity of the price with respect to time-to-sell observed in the data. The autocorrelation coefficient $\rho$ is set to 0.94 to match the empirically observed autocorrelation in house prices. We normalize the mean of $\ln \left(\varepsilon_{t}\right)$ to 0 , so $\zeta_{\varepsilon}=0$. Furthermore, we set the expected utility of buyers to be half of that from owning, which gives a $\zeta_{\varepsilon^{B}}$ of -0.042 . Lastly, $\zeta_{k}=0.231$, so that $\mathbb{E} \ln \left(k_{i}\right)=3.854$. Table 1 summarizes the calibration.

\footnotetext{
${ }^{33}$ In Shimer (2005) shocks to labor productivity affect the endogenous separation rate, but for simplicity he models labor productivity and separation shocks as perfectly correlated shocks. In his model an underlying stochastic process drives both labor productivity and separations, and the calibration ensures that their correlation is the same as in the data. The approach in this paper is similar.

${ }^{34}$ Both $\varepsilon$ and $\varepsilon^{B}$ can increase or just $\varepsilon$. As long as they do not move in opposite directions, which is reasonable, the results are the same. What matters is that in an expansion the net utility is increasing. This captures a higher utility of being a homeowner, i.e. a demand shock. In particular, the quantitative results are essentially the same when we set $\varepsilon^{B}$ equal to zero and allow shocks to $\varepsilon$ only.
} 


\section{Results}

This section shows that our model accounts for the cyclical behavior of the key variables in the housing market. In addition, to illustrate the role of the endogenous entry of buyers, we simulate a standard search model à la DMP, where all homeless agents search for homes. Effectively, this corresponds to the case where buyers' search costs are constant or decreasing. In this case the value of buyers is always positive and the measure of buyers is subject to a law of motion similar to the law of motion for unemployment in the baseline DMP. ${ }^{35}$ As expected, a standard search model of the housing market is unable to match the stylized facts qualitatively, essentially because the measure of buyers is a state variable that decreases as more houses are posted in the market.

To assess the quantitative performance of the model, we focus on the stylized facts described in the introduction, i.e. the response of sales, vacancies and time-to-sell to changes in house prices. We focus on these stylized facts for two reasons. First, much of the literature focuses on the co-movement of these variables. Most importantly, together these elasticities determine the response of the key variables in a search model of the housing market, namely vacancies, buyers, market tightness and house prices. These are the central variables in search models in any market. ${ }^{36}$ In addition, the appeal of the elasticities, as Hall and Milgrom (2008) and Mortensen and Nagypal (2007) point out, is that they correspond to a regression coefficient. Given that we are trying to explain movements in tightness, vacancies and buyers in response to movement in prices, our benchmark should be to explain the movement in these variables generated by movement in prices. This is exactly what the regression coefficient, i.e. the elasticity, captures.

We simulate the model by discretizing (23), (24), and (25) using the Rouwenhorst (1995) method to approximate AR(1) processes with a discrete Markov process. As Kopecky and Suen

\footnotetext{
${ }^{35}$ Of course, parameter values could be such that the value of being a buyer is negative. This corresponds to the equilibrium where no buyers enter the market. An implicit assumption in most search models is that model parameters are such that agents want to enter the market-for example, in the DMP model the parameters implicitly satisfy that the value of unemployment is positive. Otherwise, no worker searches for jobs or participates in the labor market.

${ }^{36}$ For example, most of the exposition of the DMP baseline model in Pissarides (2000) centers around the response of labor market tightness, vacancies, unemployment and wages to changes in some of the parameters in the model. Shimer (2005) studies the quantitative behavior of labor market tightness, wages, vacancies and unemployment in response to shocks to labor productivity and job separations shocks and shows that the baseline model is unable to match the volatility observed in the data. Mortensen and Nagypal (2007) reviews the Shimer (2005) puzzle and the literature's response by focusing on the elasticity of the labor market tightness with respect to labor productivity in different extensions of the DMP model.
} 
(2010) show, this method performs better than the method in Tauchen (1986). The AR(1) processes are approximated with 5 states. Table 2 reports the resulting transition matrix. We simulate the model 5000 times, where each simulation consists of 204 quarters. As is customary, we discard the first 20 observations so that the simulations are not affected by initial conditions.

Table 3 summarizes the results. Column 1 reports the observed elasticity of sales, time-tosell and vacancies with respect to house prices using the standard deviation and correlations in Table 5 of Diaz and Jerez (2013). Column 2 shows the results from the simulations. The model closely matches the key stylized facts observed in the data. Most notably, we are able to match the sign of the elasticity of vacancies with respect to prices. As section 3 shows, search models without buyers entry struggle to match this sign because they generate a negative Beveridge Curve between buyers and vacancies, whereas the data implies a positive relationship between buyers and vacancies. ${ }^{37}$

The response in the model to demand and supply shocks follows the dynamics described in section 2.4. A positive demand shock increases the net utility $\varepsilon-\varepsilon^{B}$. This increases buyers' surplus and leads to higher prices $p$ and an increase in the entry of buyers. Higher prices increase the incentives to create new housing, which leads to more entry of vacancies. Overall, vacancies increase more than the mass of buyers to satisfy the HE condition, since sellers are willing to tolerate higher vacancy durations (i.e. lower tightness $\theta$ ) in exchange for higher prices. This leads to a drop in the market tightness $\theta$. At the same time, a positive demand shock is associated with a higher construction cost $k$. This decreases the seller's surplus, $p-\beta k$, and disincentivizes housing construction. Hence, sellers post fewer vacancies and market tightness increases. With higher tightness, buyers take longer to find homes, which reduces the entry of buyers. Given our calibration, prices, buyers, vacancies and market tightness all increase in response to the shock. This leads to procyclical vacancies and sales, and countercyclical time-to-sell, as in the data. ${ }^{38}$

The third column of Table 3 shows the simulation results for the model without buyer entry.

\footnotetext{
${ }^{37}$ The Beveridge Curve is upward-sloping in the simulations, as expected. Similar to Hall and Milgrom (2008) we report the slope of the Beveridge Curve between the middle states. The slope is 0.82 between state 2 and state $3 ; 1.03$ between state 3 and state 4 ; and 0.97 between states 2 and 4 .

${ }^{38}$ Similar to Diaz and Jerez (2013), given the empirical behavior of sales, vacancies and tightness, we need movements in both $\varepsilon-\varepsilon^{B}$ and $k$ over the cycle. Prices increase with both higher $\varepsilon-\varepsilon^{B}$ and $k$. The observed negative elasticity of time-to-sell requires shocks to $k$, as market tightness increases with $k$ but decreases with $\varepsilon-\varepsilon^{B}$. Given that vacancies are decreasing in costs $k$ and increasing in $\varepsilon-\varepsilon^{B}$, the observed positive elasticity of vacancies requires shocks to $\varepsilon-\varepsilon^{B}$.
} 
Without buyer entry, market tightness is determined by a house entry condition similar to the one in our baseline model, whereas the mass of buyers is a state variable that follows a law of motion. A shock raises both $\varepsilon-\varepsilon^{B}$ and $k$. Overall, prices and market tightness increase to satisfy the house entry condition. Since the mass of buyers is a state variable without buyers entry, this lowers vacancies. A higher market tightness makes it harder for buyers to get matched and find a home, so sales decrease. This leads to a negative correlation of sales and vacancies with respect to prices. The model without buyer entry can still match the negative elasticity of time-to-sell and prices, but it can not match the sign of the other elasticities. As column 3 shows, the model without buyers entry also lacks amplification. The elasticity of time-to-sell is three times higher than in the data, which means that market tightness does not fluctuate enough compared to its empirical counterpart.

Column 4 shows the results in the model in Diaz and Jerez (2013), which has vacancy creation but no buyers entry. The values are calculated using the standard deviation and correlation coefficients reported in their Table 5. Their model features three imperfectly correlated shocks. In addition to demand and supply shocks, their model includes separation shocks, so over the cycle the number of homeowners who become buyers varies stochastically. A further difference is that entry in their model is not endogenous and not driven by a free entry condition, as in this paper. Although the elasticities in column 4 correspond to their model using a different calibration, and as a result they are not directly comparable to the ones in column 3 , the comparison is still useful to understand the importance of buyers entry. Compared to the model with no buyers entry, their model gets the right sign of sales by adding separation shocks, but otherwise the other two elasticities are similar to the ones in column 3. Intuitively, during an expansion homeowners may want to sell their homes more often to find a more suitable home. This is captured by a shock to separations. A positive separation shock leads to more vacancies which in turn lead to more sales. However, their model is still unable to match the sign of vacancies. Without buyers entry the Beveridge Curve between buyers and vacancies is downward sloping, so it is not possible to match the sign on all elasticities. The elasticities are also larger than in the data, which implies that there is not enough amplification in market tightness. The difficulty of matching all signs is not specific to their model. Any baseline search model of the housing market à la DMP without buyers entry features a downward sloping Beveridge Curve and is, therefore, unable to match all signs at the same time. 


\section{Conclusion}

In standard search models of the labor market, when vacancies are high unemployment is low, i.e. the Beveridge Curve is downward sloping. This is consistent with the data. By contrast, in the housing market vacancies and buyers - the equivalent of vacancies and the unemployed - are positively correlated empirically, i.e. the data imply an upward sloping Beveridge Curve. Given that baseline search models of the housing market generate a downward sloping Beveridge Curve, they struggle to match the sign of the correlations between the key variables in the model-vacancies, market tightness, buyers and prices. This paper studies a stochastic search model of the housing market with endogenous entry of both buyers and sellers. The entry of buyers delivers a positive Beveridge Curve, consistent with the data. Compared to baseline search models, an increase in the number of posted vacancies makes it easier to find a house, which induces the entry of buyers. We show that quantitatively the model accounts for the fluctuations in the key housing market variables.

We envision two extensions of this paper in future work. First, as Ngai and Sheedy (2017) point out, separations are quite volatile in the housing market. We plan on extending the current framework and allow for endogenous separations as in Mortensen and Pissarides (1994). In addition, credit plays an important role in the housing market, both to finance construction of new housing and house purchases. In Gabrovski and Ortego-Marti (2018b) we introduce credit frictions in the spirit of Rocheteau, Wright and Zhang (in press) and Wasmer and Weil (2004) to study their effect on the housing market. In future work we plan to investigate the role of credit frictions further. 


\section{References}

AnEnBerg, E. (2016). Information frictions and housing market dynamics. International Economic Review 57 (4), 1449-1479.

Arnott, R. (1989). Housing vacancies, thin markets, and idiosyncratic tastes. Journal of Real Estate Finance and Economics, 2 (1), 5-30.

Bachmann, R. and Cooper, D. (2014). The ins and arounds in the US housing market. Mimeo.

Barwick, P. J., Pathak, P. A. and Wong, M. (2017). Conflicts of interest and steering in residential brokerage. American Economic Journal: Applied Economics, 9 (3), 191-222.

Beveridge, W. H. (1944). Full Employment in a Free Society. London: George Allen and Unwin.

Burnside, C., Eichenbaum, M. and Rebelo, S. (2016). Understanding booms and busts in housing markets. Journal of Political Economy, 124 (4), 1088-1147.

Caplin, A. and Leahy, J. (2011). Trading frictions and house price dynamics. Journal of Money, Credit and Banking, 43 (s2), 283-303.

CARney, M. (1982). Costs and pricing of home brokerage services. Real Estate Economics, 10 (3), 331-354

Davis, M. A. and Heathcote, J. (2005). Housing and the business cycle. International Economic Review, 46 (3), 751-784.

Diaz, A. and Jerez, B. (2013). House prices, sales, and time on the market: A search-theoretic framework. International Economic Review, 54 (3), 837-872.

Flinn, C. J. and Heckman, J. J. (1983). Are unemployment and out of the labor force behaviorally distinct labor force states? Journal of Labor Economics, 1 (1), 28-42.

Frew, J., Jud, D. and McIntosh, W. (1993). A note on agency size and brokerage commission splits. Journal of Real Estate Research, 8 (2), 287-291.

Gabrovski, M. and Ortego-Marti, V. (2018a). Housing market dynamics with search frictions. Mimeo, University of California Riverside.

Gabrovski, M. and Ortego-Marti, V. (2018b). Search and Credit Frictions in the Housing Market. Mimeo, University of California Riverside.

Garibaldi, P. and Wasmer, E. (2005). Equilibrium search unemployment, endogenous participation, and labor market flows. Journal of the European Economic Association, 3 (4), $851-882$.

Genesove, D. and Han, L. (2012). Search and matching in the housing market. Journal of Urban Economics, 72 (1), 31-45. 
- and MAYER, C. J. (2001). Loss aversion and seller behavior: Evidence from the housing market. Quarterly Journal of Economics, 116 (4), 1233-1260.

- and Mayer, C. J. (1997). Equity and time to sale in the real estate market. American Economic Review, 87 (3), 255.

Ghent, A. (2012). Infrequent housing adjustment, limited participation, and monetary policy. Journal of Money, Credit and Banking, 44 (5), 931-955.

Glaeser, E. L. and Gyourko, J. (2006). Housing dynamics.

Glaeser, E. L. and Gyourko, J. (2007). Arbitrage in housing markets.

Goolsby, W. and Childs, B. (1988). Brokerage firm competition in real estate commission rates. Journal of Real Estate Research, 3 (2), 79-85.

Hall, R. E. (1970). Why is the unemployment rate so high at full employment? Brookings papers on economic activity, 1970 (3), 369-410.

Hall, R. E. and Milgrom, P. R. (2008). The limited influence of unemployment on the wage bargain. American Economic Review, 98 (4), pp. 1653-1674.

Han, L. and Strange, W. C. (2015). The microstructure of housing markets: Search, bargaining, and brokerage. Handbook of regional and urban economics 5, 813-886.

Head, A., Lloyd-Ellis, H. and Sun, H. (2014). Search, liquidity, and the dynamics of house prices and construction. American Economic Review, 104 (4), 1172-1210.

- - - and - (2016). Search, liquidity, and the dynamics of house prices and construction: Corrigendum. American Economic Review, 106 (4), 1214-19.

Hsieh, C.-T., Moretti, E., 2003. Can free entry be inefficient? Fixed commissions and social waste in the real estate industry. Journal of Political Economy 111 (5), 1076-1122.

Iacoviello, M. (2011). Housing wealth and consumption. International Finance Discussion Papers 1027, Board of Governors of the Federal Reserve System (U.S.), 2011.

Jones, S. R. and Riddell, W. C. (1999). The measurement of unemployment: An empirical approach. Econometrica, 67 (1), 147-162.

Jones, S. R. G. and Riddell, W. C. (2006). Unemployment and nonemployment: heterogeneities in labor market states. The Review of Economics and Statistics, 88 (2), 314-323.

Kashiwagi, M. (2014a). A search-theoretic model of the rental and homeownership markets. Journal of Housing Economics, 26, 33-47.

- (2014b). Sunspots and self-fulfilling beliefs in the US housing market. Review of Economic Dynamics, 17 (4), 654-676.

Kopecky, K. A. and Suen, R. M. (2010). Finite state markov-chain approximations to highly persistent processes. Review of Economic Dynamics, 13 (3), 701-714. 
KRAINER, J. (2001). A theory of liquidity in residential real estate markets. Journal of Urban Economics, 49 (1), 32-53.

- et al. (2008). Falling house prices and rising time on the market. FRBSF Economic Letter.

Luchs, R. J. and Prescott, E. C. (1974). Equilibrium search and unemployment. Journal of Economic Theory, 7 (2), 188-209.

Mortensen, D. T. and Nagypal, E. (2007). More on unemployment and vacancy fluctuations. Review of Economic Dynamics, 10 (3), 327 - 347.

- and Pissarides, C. A. (1994). Job creation and job destruction in the theory of unemployment. Review of Economic Studies, 61 (0), 397-415.

Nash, J., John F. (1950). The bargaining problem. Econometrica, 18 (2), pp. 155-162.

NGai, L. R. and SheEdy, K. D. (2015). The ins and outs of selling houses. Mimeo, London School of Economics.

Ngai, L. R. and Sheedy, K. D. (2017). Moving House. Mimeo, London School of Economics.

- and Tenreyro, S. (2014). Hot and cold seasons in the housing market. American Economic Review, 104 (12), 3991-4026.

Novy-Marx, R. (2009). Hot and cold markets. Real Estate Economics, 37 (1), 1-22.

Ortalo-Magne, F. and RAdy, S. (2006). Housing market dynamics: On the contribution of income shocks and credit constraints. Review of Economic Studies, 73 (2), 459-485.

Piazzesi, M. and Schneider, M. (2009). Momentum traders in the housing market: Survey evidence and a search model. American Economic Review, 99 (2), 406-11.

- and - (2016). Chapter 19 - Housing and Macroeconomics. Handbook of Macroeconomics, vol. 2, Elsevier, pp. $1547-1640$.

Pissarides, C. A. (2000). Equilibrium Unemployment Theory. Cambridge: MIT Press.

Rocheteau, G., Wright, R. and Zhang, C. (in press). Corporate finance and monetary policy. Forthcoming, American Economic Review.

Rouwenhorst, G. (1995). Asset pricing implications of equilibrium business cycle models. Frontiers of Business Cycle Research, pp. 294-330.

Rubinstein, A. (1982). Perfect equilibrium in a bargaining model. Econometrica, 50 (1), 97-109.

Schnare, A. and Kulick, R. (2009). Do real estate agents compete on price? evidence from seven metropolitan areas.

Shimer, R. (2005). The cyclical behavior of equilibrium unemployment and vacancies. American Economic Review, 95 (1), 24-49. 
- (2007). Mismatch. American Economic Review, 97 (4), 1074-1101.

Sirmans, C. F. and Turnbull, G. K. (1997). Brokerage pricing under competition. Journal of Urban Economics, 41 (1), 102-117.

Smith, E. (2015). High and low activity spells in housing markets. Mimeo.

Stein, J. C. (1995). Prices and trading volume in the housing market: A model with downpayment effects. Quarterly Journal of Economics, 110 (2), 379-406.

Tauchen, G. (1986). Finite state markov-chain approximations to univariate and vector autoregressions. Economics letters, 20 (2), 177-181.

Van Nieuwerburgh, S. and Weill, P.-O. (2010). Why has house price dispersion gone up? Review of Economic Studies, 77 (4), 1567-1606.

Wasmer, E. and WeIL, P. (2004). The macroeconomics of labor and credit market imperfections. American Economic Review, 94 (4), 944-963.

Wheaton, W. C. (1990). Vacancy, search, and prices in a housing market matching model. Journal of Political Economy, 98 (6), 1270-1292.

Zietz, J. and Newsome, B. (2001). A note on buyer's agent commission and sale price. Journal of Real Estate Research, 21 (3), 245-254. 
Table 1: CALIBRATION

\begin{tabular}{|c|c|c|c|}
\hline Preferences/Technology & Parameter & Value & Source/Target \\
\hline Discount Factor & $\beta$ & 0.986 & $\begin{array}{l}6 \% \text { annual interest rate } \\
\text { Ngai and Tenreyro (2014) }\end{array}$ \\
\hline Homeowner Utility & $\mathbb{E} \ln \left(\varepsilon_{i}\right)$ & 0 & Normalization \\
\hline Buyer Utility & $\mathbb{E} \ln \left(\varepsilon_{i}^{B}\right)$ & -0.693 & \\
\hline Investor Cost & $c^{R}$ & 0.564 & Normalize $\mathbb{E} b_{i}=1$ \\
\hline Destruction & $\delta$ & 0.004 & $\begin{array}{l}1.6 \% \text { annual depr. rate } \\
\text { Van Nieuwerburgh and Weill (2010) }\end{array}$ \\
\hline Separations & $s$ & 0.024 & $\begin{array}{l}9 \text { years tenure } \\
\text { Diaz and Jerez (2013) }\end{array}$ \\
\hline Bargaining Power & $\eta$ & 0.5 & Ngai and Sheedy (2017) \\
\hline Elasticity of $m(\theta)$ & $\alpha$ & 0.16 & Genesove and Han (2012) \\
\hline Construction Cost & $\mathbb{E} \ln \left(k_{i}\right)$ & 3.854 & $\begin{array}{l}\text { Time-To-Sell }=2 \text { quarters } \\
\text { Ngai and Sheedy (2017) }\end{array}$ \\
\hline Matching Efficiency & $\mu$ & 0.5 & Time-To-Buy = 2 quarters \\
\hline Elasticity of Cost & $\gamma$ & 0.4 & \\
\hline Cost Scale & $\bar{c}$ & 2.117 & $\begin{array}{l}\text { Buyer's transaction costs }=8 \% \\
\text { of home value Ghent }(2012)\end{array}$ \\
\hline Volatility of Shock & $\sigma_{u}$ & $14.29 \%$ & $\mathrm{SD}(p)=4.1 \%$ \\
\hline $\begin{array}{l}\text { Volatility of } \\
\text { Construction Cost }\end{array}$ & $a$ & 0.218 & $\begin{array}{l}\text { Elasticity of Price } \\
\text { wrt TTS }=-0.12\end{array}$ \\
\hline Autocorrelation & $\rho$ & 0.94 & $\begin{array}{l}\text { Autocorrelation of price }=0.94 \\
\text { Diaz and Jerez }(2013)\end{array}$ \\
\hline
\end{tabular}


Table 2: Transition MATRIX

\begin{tabular}{ccccccc}
\hline \hline & & \multicolumn{5}{c}{ To State } \\
\hline & 1 & 0.8853 & 0.1095 & 0.0051 & 0.0001 & \\
& 2 & 0.0274 & 0.8879 & 0.0822 & 0.0025 & \\
From State & 3 & 0.0008 & 0.0548 & 0.8888 & 0.0548 & 0.0008 \\
& 4 & & 0.0025 & 0.0822 & 0.8879 & 0.0274 \\
& 5 & & 0.0001 & 0.0051 & 0.1095 & 0.8853 \\
\hline
\end{tabular}

Note.- Transition matrix for the stochastic shocks using Rouwenhorst (1995) method. This transition matrix governs demand and supply shocks in the business cycle simulations. 
Table 3: Results

\begin{tabular}{crrcc}
\hline Elasticity of $p$ wrt & Data & Model & No Entry & Diaz and Jerez (2013) \\
\hline Sales & 0.14 & 0.13 & -1.37 & 0.26 \\
Time-To-Sell & -0.12 & -0.12 & -0.33 & -0.31 \\
Vacancies & 0.06 & 0.12 & -0.30 & -0.24 \\
\hline
\end{tabular}

Note.- The first column shows the data statistics from Diaz and Jerez (2013). The second column shows the model with entry of buyers and sellers. The third column shows the model with no entry of buyers, which corresponds to a constant or decreasing cost $c^{B}(b)$. The final column reports the elasticities in the model of Diaz and Jerez (2013), using their calibration and as reported in their Table 5, p. 856. 